\title{
A educação CTS possui respaldo em documentos oficiais brasileiros?
}

Roseline Beatriz Strieder roseline@unb.br

Universidade de Brasília (UnB), Brasília, Distrito Federal, Brasil

Karolina Martins Almeida e Silva karolinaeducabio@gmail.com Universidade Federal do Tocantins (UFT) Araguaína, Tocantins, Brasil

Marcos Fernandes Sobrinho marcos.sbf@gmail.com Instituto Federal Goiano (IF Goiano), Urutaí, Goiás, Brasil

Wildson Luiz Pereira dos Santos wildson@unb.br

Universidade de Brasília (UnB), Brasília, Distrito Federal, Brasil

\section{RESUMO}

Neste artigo, discutem-se possibilidades e desafios associados ao desenvolvimento de práticas educativas CTS, no contexto da educação científica brasileira. Para tanto, analisaram-se diferentes documentos oficiais, voltados à educação científica e ao ensino médio, publicados depois da atual Lei de Diretrizes e Bases da Educação Nacional. Os resultados indicam que a educação CTS possui respaldo nos documentos analisados, ainda que em abordagens pouco críticas. Assim, conclui-se pela viabilidade da educação CTS no contexto educacional brasileiro e que para sua ampliação, em especial em perspectivas críticas, são necessárias discussões em espaços de formação de professores.

PALAVRAS-CHAVE: CTS. Ensino Médio. Documentos educacionais oficiais. 


\section{INTRODUÇÃO}

No contexto educacional brasileiro, durante a década de 1980, passou a ser reivindicado um ensino de Ciências que contribuísse para a compreensão e uso da tecnologia e para a consolidação da democracia, influenciando discussões sobre ciência-tecnologia-sociedade (CTS) (AMORIM, 1995). Desde então, têm crescido o interesse e preocupações em torno dessa temática, aumentando, também, a diversidade de propostas (STRIEDER, 2012). Dentre as diferentes visões de CTS, destacamos a perspectiva crítica que encontra respaldo nos pressupostos do educador brasileiro Paulo Freire e do Pensamento Latino Americano em CTS (PLACTS), a qual tem sido defendida em nosso grupo de pesquisa "Educação Científica e Cidadania" vinculado à Universidade de Brasília.

Entendendo que mudanças no âmbito político e econômico interferem no sistema educacional, e expressam-se por meio do currículo e que "nesta perspectiva, não existe nenhum currículo neutro e imparcial, nem tampouco um conhecimento escolar absoluto e imutável" (LOPES, 1999, p. 22), resolvemos analisar como políticas públicas no Brasil estão relacionadas à CTS. Mais especificamente, decidimos investigar se documentos curriculares oficiais brasileiros estão de acordo com essa perspectiva.

Vale lembrar que muitos trabalhos fundamentados pela educação CTS afirmam que essa perspectiva encontra respaldo nos documentos oficias brasileiros (PINHEIRO; WESTPHAL; PINHEIRO, 2005; PINHEIRO; SILVEIRA; BAZZO, 2007). Por outro lado, há autores que apontam que há uma série de questões presentes nesses documentos que merecem atenção, a exemplo dos conceitos de cidadania (CUNHA, 2005; ORIANI, 2007; MOEHLECKE, 2012; TOTI, 2011), competências (RICARDO, 2005; PAIVA; KAWAMURA, 2016), interdisciplinaridade e contextualização (RICARDO, 2005) e relações entre desenvolvimento tecnológico e os processos de produção da sociedade (LOPES, 2004; LEODORO, 2008).

Diante disso, consideramos pertinente uma análise sobre em que sentido e até que ponto discussões CTS são recomendadas em documentos oficiais brasileiros, tanto para buscar espaços curriculares para essa perspectiva, como no intuito de desvelar concepções ingênuas que possam deturpar os objetivos de uma educação CTS crítica. Essa análise, desenvolvida neste artigo, tem como propósito identificar: (a) se a educação CTS é possível no contexto da educação científica brasileira; e (b) desafios associados ao desenvolvimento de práticas educativas CTS no Brasil.

\section{EDUCAÇÃO CTS EM UMA PERSPECTIVA CRÍTICA}

A educação CTS tem sido proposta com o objetivo da formação para a cidadania (SANTOS, 2012). Nesse sentido, entende-se que ela não é a mera discussão da ciência e da tecnologia (C\&T) inseridas no contexto social, mas a efetiva articulação entre ambas, o que se dá a partir de três parâmetros: (a) Racionalidade Científica, (b) Desenvolvimento Tecnológico e (c) Participação Social, na perspectiva do desenvolvimento de compromissos sociais (STRIEDER, 2012).

Essa perspectiva (dos compromissos sociais), segundo Strieder (2012), envolve o desenvolvimento de competências para que a sociedade possa lidar com 
problemas de diferentes naturezas, tendo condições de fazer uma leitura crítica da realidade. Isso está associado à busca por encaminhamentos para problemas reais que afligem a sociedade com a qual a escola se encontra; envolve, assim, ações concretas de intervenção na realidade. Implica, por exemplo, discutir limitações do conhecimento científico para compreender e resolver problemas sociais; enfatizar a importância de a sociedade almejar outro modelo de desenvolvimento, que busque satisfazer as necessidades básicas de uma determinada população e não somente gerar lucro econômico; e, buscar uma cultura de participação no âmbito das políticas públicas, na definição de objetivos, meios para alcançá-los e maneiras de controlar sua implementação. Perpassa, também, pela compreensão da presença da C\&T no mundo; de questões técnicas como o funcionamento de aparatos tecnológicos; dos antecedentes sociais e das implicações sociais da C\&T, com destaque para a não neutralidade da produção científico-tecnológica.

Essa caracterização da educação CTS tem sido vista pelo nosso grupo dentro de uma perspectiva que denominamos crítica, no sentido de contrapor a visão reducionista criticada por Auler e Delizoicov (2001), marcada pela neutralidade da ciência. Essa visão crítica, está fundamentada nos princípios do PLACTS e da perspectiva de educação emancipadora de Paulo Freire. O PLACTS contesta a visão de modelo linear segundo o qual toda inovação tecnológica segue um padrão bem definido de descoberta científica e de desenvolvimento de produtos e defende o desenvolvimento de políticas de C\&T, centradas na participação social (DAGNINO; SILVA; PADOVANNI, 2011). A educação emancipadora para Paulo Freire é centrada na mediação, na dialogicidade e na investigação temática. Essa educação, para Freire (1970) é problematizadora, de caráter reflexivo, de desvelamento da realidade.

Sob esse ponto de vista, portanto, almeja-se a formação de cidadãos que compreendam a atividade científico-tecnológica e suas relações com a sociedade, que saibam se posicionar diante dela, assumam responsabilidades e, além disso, sejam capazes de intervir socialmente. Vale ressaltar que, como destacado em Strieder (2012), essa perspectiva está relacionada a uma mudança no currículo escolar e, principalmente, na função social da escola. Também, de acordo com a autora, para alcançar seus objetivos são necessárias intervenções curriculares sucessivas, com graus de complexidade variados e complementares.

\section{ENCAMINHAMENTOS METODOLÓGICOS}

Este estudo está centrado no ensino de Ciências no Ensino Médio e, portanto, foram objetos de análise em nossas investigações os documentos relativos ao ensino de Biologia, Física e Química desse nível de ensino, quais sejam: as Diretrizes Curriculares Nacionais para o Ensino Médio publicadas em 1998 DCNEM/98, incluindo a Resolução CEB no 3/98 e o Parecer CEB/CNE no 15/98 (BRASIL, 1998a; BRASIL, 1998b); os Parâmetros Curriculares Nacionais para o Ensino Médio - PCNEM (BRASIL, 1999); as Orientações Complementares aos PCNEM - PCN+ (BRASIL, 2002); as Orientações Curriculares Nacionais para o Ensino Médio - OCNEM (BRASIL, 2006); as novas Diretrizes Curriculares Nacionais publicadas em 2013 - DCN/13 (BRASIL, 2013a); o edital de convocação para o processo de inscrição e avaliação de obras didáticas do Programa Nacional de Livro Nacional do Ensino Médio de 2016- MR-ENEM/16 (BRASIL, 2016a) e a 2a versão 
revista da Base Nacional Comum Curricular publicada em 2016 - BNCC/16 (BRASIL, 2016b).

Entendemos que os documentos analisados são, de certa maneira, representativos de políticas públicas de reforma educacional do ensino médio e se configuram em importantes ferramentas para a reflexão sobre o contexto curricular brasileiro. Deve-se considerar ainda que, embora as DCNEM/98, os PCNEM, PCN+ e OCNEM tenham sido revogados pelas DCN/13, esses documentos são os que orientaram a prática docente por mais de uma década. Sabe-se também que essas novas DCN ainda não estão consolidadas e carecem de maiores orientações que se espera serem complementadas com a publicação de novos documentos como a BNCC, também objeto de análise desta investigação. Quanto ao edital do PNLD e à MR-ENEM, esclarecemos que analisamos somente as versões mais recentes desses documentos, publicadas nos anos de 2013 e de 2016, respectivamente.

Como não temos pretensão de realizar comparações, as análises foram feitas por documento e orientadas pelos pressupostos teóricos anteriormente apresentados e pela Análise Textual Discursiva (MORAES; GALIAZZI, 2007). Após selecionar os documentos, procedemos à leitura e desconstrução de cada um, na perspectiva de identificar e destacar enunciados de interesse, relacionados à CTS. Esses enunciados (frases, parágrafos ou partes maiores dos textos), foram reunidos em grupos que abarcam elementos comuns e, a partir disso, emergiram categorias que foram o ponto de partida para a produção, sob a forma de metatextos, das descrições e interpretações possibilitadas pela análise. Certamente essas categorias não esgotam as análises e discussões possíveis de serem realizadas, mas, ajudam-nos a perceber algumas sinalizações CTS, explícitas e implícitas nesses documentos.

\section{SINALIZAÇÕES DA EDUCAÇÃO CTS}

Os resultados encontrados são apresentados na seguinte ordem: (1) DCNEM/98; (2) Orientações complementares às DCNEM/98: PCNEM, PCN+ e OCNEM; (3) DCN/13; (4) PNLD/15; (5) MR-ENEM/16 e (6) BNCC/16.

\section{(1) Diretrizes Curriculares Nacionais do Ensino Médio de 1998}

As DCNEM/98 foram propostas a partir da Lei de Diretrizes e Bases da Educação promulgada em 1996 (LDBEM 9304/96) (BRASIL, 1996). Como colocado no parecer elaborado pelo Conselho Nacional de Educação (BRASIL, 1998b), a LDBEM estabelece diretrizes gerais enquanto as DCNEM propõem diretrizes que se aproximam mais da ação pedagógica, "são indicações para um acordo de ações e requerem revisão mais frequente" (grifo dos autores, p.4). Da análise que realizamos desse documento (Resolução e Parecer), destacamos três questões relacionadas à CTS: a) formação para o exercício da cidadania; b) contribuições formativas das ciências da natureza (CN) e suas tecnologias; c) abordagens de tecnologia.

A formação para o exercício da cidadania é enfatizada tanto na Resolução quanto no Parecer e, também, no âmbito da educação CTS. Porém, vale lembrar 
que cidadania é um termo polissêmico (TOTI, 2011) e na Resolução não é explicitado o conceito de cidadania assumido. Por outro lado, no Parecer há uma perspectiva explícita de cidadania e de acordo com análises realizadas por outros autores (CUNHA, 2005; ORIANI, 2007), uma tendência "limitada ao solidário, ao voluntariado e às ações funcionais ao mercado/consumo" (ORIANI, 2007, p. 317), ou seja, que parecem distanciar-se da concepção de cidadania proposta na educação CTS (SANTOS, 2012). De fato, a partir da análise realizada, foi possível perceber que a cidadania, a participação social ou o protagonismo, estão associados ao momento pós-produção da $\mathrm{CT}$, à assimilação de produtos tecnológicos, ao uso adequado dos recursos naturais e/ou à execução de políticas determinadas em outras instâncias (ver páginas 14, 45 e 46 do Parecer). Não comparecem discussões com relação à participação no âmbito da elaboração de políticas públicas ou de desvelar o contexto de exploração da sociedade, como tem sido defendido na educação CTS (STRIEDER, 2012; SANTOS, 2008). Vale colocar que reflexões críticas sobre as inter-relações CTS representam uma das dimensões necessárias à educação para a cidadania (SANTOS, 2012) e, sendo assim, "excluir a educação CTS da educação para a cidadania é lhes retirar um domínio central no sentido da preparação do cidadão para a tomada de decisão de questões relativas à ciência e à tecnologia." (SANTOS, 2012, p. 58-59).

Quanto às contribuições da área de Ciências da Natureza, Matemática e suas Tecnologias, explicitadas no Artigo 10 da Resolução, destacamos que há uma preocupação em aproximar o conhecimento científico do cotidiano dos alunos, contribuindo para que esses compreendam a realidade (em especial, nos itens " $b$ " $a$ " $h$ " e " $m$ " do referido artigo). Além disso, há uma preocupação com as implicações da C\&T (expressa nos itens "a", "i" a "I"), com destaque para a necessidade de se compreender as ciências como construções humanas e entender a relação entre $C \& T$, seus usos, contribuições e impactos na sociedade. Por outro lado, não são pontuados aspectos que permitem um olhar questionador sobre o desenvolvimento científico-tecnológico, em especial, sobre sua suposta neutralidade. Da mesma maneira, não há proposições mais próximas à perspectiva dos compromissos sociais, por exemplo, associadas à abordagem das limitações do conhecimento científico para compreender e resolver problemas sociais.

Por fim, também ressaltamos a questão da tecnologia, que recebe um destaque especial no contexto educacional brasileiro com a promulgação dessas diretrizes. No Parecer, em especial na página 47, há um reconhecimento sobre a importância de compreensões a respeito dos produtos da tecnologia em suas relações com o conhecimento científico. Mas, não comparece uma preocupação com análises mais críticas sobre o desenvolvimento e suas implicações na sociedade, como proposto nos estudos CTS. Assim, mais uma vez, percebemos que há discussões que se aproximam do que é almejado no âmbito da educação CTS, porém, em um ponto de vista menos crítico.

\section{(2) Orientações complementares às DCNEM/98: PCNEM, PCN+ e OCNEM}

Os PCNEM, PCN+ e OCNEM, publicados, respectivamente, nos anos de 1999, 2002 e 2006 fazem parte da política de reforma do Ensino Médio proveniente da promulgação da LDBEN 9.394/96 e instituição das DCNEM/98. Em função disso, optamos por apresentar os resultados da análise desses documentos em um mesmo item. Porém, ressaltamos que os textos que compõem esses documentos 
são de autores diferentes e foram elaborados em épocas e com propósitos distintos e, assim, nem sempre, estão voltados a uma matriz conceitual comum (LOPES, 2002; RICARDO, 2005). Mesmo assim foi possível organizar os resultados dessa análise a partir de três categorias, quais sejam: a) menção às inter-relações CTS; b) abordagem de aspectos sociocientíficos (ASC); c) interdisciplinaridade, contextualização e abordagem de temas.

a) Menção às inter-relações CTS

Nos documentos analisados há várias menções às inter-relações CTS, ainda que não por meio dessa terminologia. Como evidenciado nos PCNEM, os "objetivos explicitamente atribuídos à área de Ciências e Matemática incluem compreender as Ciências da Natureza como construções humanas e a relação entre conhecimento científico tecnológico e a vida social e produtiva" (p. 11). Essa descrição denota claramente aspectos relacionais entre CTS, que também são mencionados nos outros documentos e em tópicos referentes aos componentes curriculares dessa área. Por exemplo, no PCN+, identificamos uma clara indicação das inter-relações CTS quando caracteriza as disciplinas das CN como componentes de uma mesma área do conhecimento por terem como objeto de estudo comum a investigação da natureza e dos desenvolvimentos tecnológicos. Associado a isso, o documento ressalta que as disciplinas da área compõem a cultura científicotecnológica, reconhecida como fruto de uma construção histórica que sofre influências econômicas e sociais. As OCNEM, por sua vez, apresentam um termo que não havia sido mencionado nos demais documento, a alfabetização científica. De acordo com o documento, esse conceito implica três dimensões: "a aquisição de um vocabulário básico de conceitos científicos, a compreensão da natureza do método científico e a compreensão sobre o impacto da ciência e da tecnologia sobre os indivíduos e a sociedade" (p. 18, grifo nosso). Ou seja, também nas OCNEM há menção às inter-relações CTS, porém a ênfase está em análises pósprodução.

Além disso, em discussões associadas à Biologia há menções à CTS nos PCNEM, $\mathrm{PCN}+$ e nas OCNEM. Nesse último, por exemplo, o referido componente curricular retoma as discussões sobre a abordagem das inter-relações CTS com o foco voltado ao desenvolvimento de competências relativas à "contextualização sociocultural" que denota claramente os eixos articuladores voltados à análise da C\&T em relação: à história, à cultura, à atualidade, ética e cidadania (p. 39-40). Em relação aos conhecimentos de Física, nos PCNEM não há menção explícita às interrelações CTS. Porém, há uma defesa pela abordagem dos conceitos específicos por meio de temas, que são exemplificados e justificados em função "da vida individual, social e profissional, presente e futura, dos jovens que frequentam a escola média" (p. 28). Nos PCN+ (2002), o componente curricular da física, retoma a importância de um trabalho integrado, como mencionado no PCNEM, e justifica a necessidade de desenvolver competências para essa finalidade e, associado a isso, faz referência às inter-relações CTS. Nesse sentido, explicita que, analisar, argumentar e posicionar-se criticamente em relação a temas de C\&T, são capacidades a serem desenvolvidas. Também, destaca a importância do educando em: "compreender o conhecimento científico e o tecnológico como resultados de uma construção humana, inseridos em um processo histórico e social" (p. 67). Além disso, apresenta o conhecimento específico da Física com destaque para as 
relações entre C\&T e história, cultura contemporânea, atualidade, ética e cidadania. O componente Química, por sua vez, segue nos PCN+ as mesmas proposições da Biologia e Física, no sentido em que denota a C\&T como indicativos no desenvolvimento de capacidades formativas para o exercício da cidadania; como pode ser observado na competência "contextualização sociocultural": "Compreender e avaliar a ciência e tecnologia química sob o ponto de vista ético para exercer a cidadania com responsabilidade, integridade e respeito; por exemplo, no debate sobre fontes de energia" (p. 93).

Os documentos analisados, portanto, explicitam um caráter de natureza mais metodológica acerca das inter-relações CTS, sob o ponto de vista da abordagem dos conteúdos da área de $\mathrm{CN}$ e da integração com as demais áreas. Porém, é importante ressaltar que discussões que visam as relações entre as dimensões científica, tecnológica e social também denotam de uma análise sob o ponto de vista filosófico e epistêmico, ou seja, de aspectos sobre a natureza, história e filosofia da ciência e da tecnologia, bem como as influências sociais e vice-versa. Nesse sentido, é preciso cautela frente às proposições CTS indicadas nos documentos pois podem favorecer ações ingênuas ou até mesmo compreensões deturpadas sobre as orientações de uma educação CTS.

b) abordagem de aspectos sociocientíficos (ASC)

A educação CTS implica a redefinição de temas sociais próprios ao contexto educacional local, ou que sejam adaptados à problemática brasileira (SANTOS, 2008). Isso por sua vez compreende a abordagem de aspectos sociocientíficos (ASC), entendidos como os aspectos históricos, políticos, econômicos, sociais, culturais, ambientais éticos e morais relacionados à C\&T (SANTOS; MORTIMER, 2009). Os documentos analisados, em geral evidenciam a abordagem de ASC relacionados à C\&T articulados pela abordagem de competências atribuídas a cada componente curricular da área de CN. Denotam a função social do ensino de ciências, expressa pela formação cidadã, como indicado no seguinte trecho relacionado ao componente curricular da Biologia:

[...] identificando aspectos éticos, morais, políticos e econômicos envolvidos na produção científica e tecnológica, bem como na sua utilização, o aluno se transporta de um cenário meramente científico para um contexto em que estão envolvidos vários aspectos da vida humana. (BRASIL, 1999, p. 19, grifo nosso).

No que compete ao componente curricular da Física, identificamos menos descrições, quando comparado à Biologia e Química. Mas, nesse caso, por exemplo, são comuns expressões sobre a importância em se reconhecer riscos/benefícios de determinadas técnicas para se avaliar as informações e emitir juízos de valor, como identificado nos trechos a seguir:

Ao mesmo tempo, devem ser promovidas as competências necessárias para a avaliação da veracidade de informações ou para a emissão de opiniões e juízos de valor em relação a situações sociais [...] (BRASIL, 1999, p. 28, grifo nosso). agrícolas ou uso de energia nuclear, entra também o debate ético e político, 
na medida em que esse uso compromete a própria existência humana (BRASIL, 2002, p. 47, grifo nosso).

Em outra vertente, encaixam-se trechos da química, compreendidos como aqueles que apresentam notória relação entre o conhecimento de química, as discussões dos ASC e tecnológicos e o desenvolvimento da tomada de decisão comprometida com a cidadania, como evidenciado a seguir:

[...] A discussão de aspectos sociocientíficos articuladamente aos conteúdos químicos e aos contextos é fundamental, pois propicia que [...] desenvolvam a capacidade de tomada de decisão com maior responsabilidade, na qualidade de cidadãos, sobre questões relativas à Química e à Tecnologia, e desenvolvam também atitudes e valores comprometidos com a cidadania [...] (BRASIL, 2006, p. 119, grifo nosso).

Como observado nos trechos acima, todos os componentes curriculares da área de $\mathrm{CN}$ indicam em maior ou menor grau de exemplificações, a abordagem de ASC relacionados a CTS. Em suma, são evidenciados como fatores voltados à compreensão mais ampla dos conceitos específicos e, quando abordados, tendem a contribuir com a superação de um enfoque conteudista. Nesse sentido, os ASC estão associados à problematização da atividade científico-tecnológica, contextualização sócio-histórica e cultural e abordagem de temas estruturantes.

c) Interdisciplinaridade, contextualização e abordagem de temas

Com relação ao termo interdisciplinaridade, reconhecemos que ele apresenta conotação polissêmica no contexto educativo global, delineando concepções, objetivos e práticas específicas que demandam de uma análise mais orientada sobre o mesmo (LENOIR, 2001). Frente a isso, nossas análises sobre o referido termo se atentaram às descrições sob o ponto de vista "conceitual e relacional", ou seja, como os documentos conceituam interdisciplinaridade e o desenvolvimento dessas práticas na área de $\mathrm{CN}$.

De acordo com os PCNEM, a interdisciplinaridade é conceituada como uma prática que recorre à utilização de conhecimentos específicos oriundos das disciplinas para resolução de um problema ou compreensão de um determinado fenômeno sob diferentes pontos de vista. O documento descreve que: "Em suma, a interdisciplinaridade tem uma função instrumental. Trata-se de recorrer a um saber diretamente útil e utilizável para responder às questões e aos problemas sociais contemporâneos" (p. 21, grifo nosso). Ou ainda, sobre o aspecto relacional, quando evidencia que a interdisciplinaridade não ocorre somente na relação entre as disciplinas, mas também no interior das mesmas: "[...] a ideia de que a perspectiva interdisciplinar de conteúdos educacionais apresentados com contexto, no âmbito de uma ou mais áreas, não precisa necessariamente de uma reunião de disciplinas, pois pode ser realizada em uma única" (p.17, grifo nosso).

Em relação aos $\mathrm{PCN}+$ e OCNEM, identificamos termos que explicitam a importância e necessidade de práticas interdisciplinares, tais como: "relação entre diferentes campos do conhecimento"; "integração entre conteúdos"; "projetos interdisciplinares"; "organização curricular por meio de temas". Assim, salientamos que o termo interdisciplinaridade comparece conceitualmente nos documentos curriculares como um instrumento que tende a contribuir com a 
relação entre os diferentes campos de conhecimento, com objetivo geral em produzir saberes que sejam úteis às demandas sociais. O que se aproxima do defendido no âmbito da educação CTS. Nesse caso, a interdisciplinaridade não se limita a buscar interfaces entre as disciplinas escolares, mas, centra-se na efetiva articulação entre olhares distintos, organizados em torno de uma temática comum, com vistas à compreensão e atuação na realidade (AULER, 2007).

Além disso, cabe destacar a proposição articuladora entre a interdisciplinaridade e a contextualização, presente nos PCNEM, conforme descrito: "[...] ou seja, porque se aprende e se percebe o aprendido apenas em situações reais, que, numa abordagem por competências, o contexto e a interdisciplinaridade são essenciais." (p. 35, grifo nosso).

Ao se referir à contextualização, o PCNEM, abarca competências de inserção da ciência e de suas tecnologias em um processo histórico, social e cultural; busca envolver o reconhecimento e discussão de aspectos práticos e éticos da ciência no mundo contemporâneo. Esse reconhecimento, de acordo com Silva (2010), expressa um grande avanço no que se refere ao aspecto conceitual acerca do enfoque CTS, pois identifica claramente a C\&T como produto da construção humana, e que passa a ser vista como parte integrante da sociedade atual, evidenciando o processo de dominação dos sistemas tecnológicos.

Também, na educação CTS, a contextualização comparece atrelada à problematização e situações reais, à busca por encaminhamentos para problemas e dilemas que afligem a sociedade contemporânea os quais podem ser abordados por meio de temas (SANTOS, 2007) e, nesse sentido, outro aspecto a destacar, refere-se à abordagem por temas. Santos e Mortimer (2002) ressaltam que o estudo por meio de temas: “(...) permite a introdução de problemas sociais a serem discutidos pelos alunos, propiciando o desenvolvimento da capacidade de tomada de decisão." (p. 13). Diante disso, ressaltamos que embora nos documentos curriculares analisados são propostos "temas estruturantes" para abordagem dos conceitos químicos, físicos e biológicos, reconhecemos algumas limitações referentes aos pressupostos CTS. Por exemplo, esses temas centram-se na contextualização dos conteúdos, na busca por aproximar os conhecimentos científicos da realidade dos alunos, e comparecem em um formato préestabelecido, não reconhecendo o professor como organizador de seu currículo, o que poderá contribuir para "engessar" possibilidades interdisciplinares de abordagem temática e o desenvolvimento de compromissos em torno de problemas sociais.

\section{(3) Diretrizes Curriculares Nacionais de 2013}

De acordo com as DCN/13, a necessidade de sua atualização surgiu da constatação de modificações relacionadas ao Ensino Fundamental (tempo de nove anos) e obrigatoriedade do ensino gratuito dos quatro aos 17 anos de idade, as quais deixaram as Diretrizes anteriores, de 1998, defasadas. Além disso, o documento enfatiza que, mesmo que as proposições curriculares apresentadas anteriormente (PCNEM, PCN+, OCNEM) tenham buscado contribuir com a compreensão acerca do trabalho didático-pedagógico e das possibilidades de organização do Ensino Médio, ainda "tem-se a percepção que tal discussão não chegou às escolas, mantendo-se atenção extrema no tratamento de conteúdos 
sem a articulação com o contexto do estudante e com os demais componentes das áreas de conhecimento" (p. 154). Nesse sentido, o documento explicita aspectos conceituais sobre o trabalho, a ciência, a tecnologia e a cultura, entendidos como dimensões da formação humana integral e, no que compete à organização curricular do Ensino Médio, indica algumas possibilidades sobre como os componentes curriculares podem ser abordados de modo a contribuir para essa formação. Associado a isso, sinaliza que as atividades integradoras de natureza interdisciplinar indiquem práticas sociais concretas (ou simulações) que consideram os conteúdos disciplinares como condutores na articulação entre o trabalho e as demais dimensões, como afirmado: “(...) compreender como o trabalho, enquanto mediação primeira entre o ser humano e o meio ambiente, produz social e historicamente ciência e tecnologia e é influenciado e influencia a cultura dos grupos sociais" (p. 185).

Em outras palavras, esse documento estabelece que as bases curriculares voltadas ao Ensino Médio permaneçam no mesmo sentido dos documentos curriculares anteriores. Mas, sinaliza, com maior detalhamento, os elementos conceituais orientadores: trabalho, a ciência, a tecnologia e a cultura. Ou seja, assim como os documentos anteriores, mantem como foco "uma formação que desenvolva autonomia e pensamento crítico, de modo que os estudantes possam atuar na sociedade de maneira refletida e relevante" (PAIVA; KAWAMURA, 2016, p.8-9).

Vale ressaltar que em seguida à publicação dessas diretrizes, o Governo Federal lançou o Programa Pacto Nacional pelo Fortalecimento do Ensino Médio, que tinha uma das suas ações centradas na promoção da formação continuada dos professores e coordenadores pedagógicos. Essa ação foi levada a cabo por meio de cursos desenvolvidos com base em materiais produzidos para esse fim - os cadernos de formação. Estamos chamando atenção para isso porque o Caderno de CN apresenta a educação CTS como uma perspectiva que pode fundamentar práticas educativas coerentes às $\mathrm{DCN} / 13$, que levam em conta interações entre trabalho, ciência, tecnologia, cultura, sociedade e o ambiente, como explicita o fragmento a seguir:

Por fim, defendemos que desenvolver os conhecimentos da Biologia, Física e Química de forma integrada, dentro de uma perspectiva CTS, possibilita a interligação dos saberes desta com as demais áreas, uma vez que podem ser trabalhados a partir de conhecimentos e temas oriundos do mundo do trabalho, da ciência, da tecnologia e da cultura. Assim, é possível construir uma visão de mundo mais ampla, articulada e menos fragmentada, propiciando aos sujeitos do Ensino Médio o protagonismo da construção de uma sociedade em constante transformação. (BRASIL, 2014, p.28)

Nessa linha, os autores esclarecem que a educação CTS se caracterizada "pela organização dos conceitos a serem ensinados a partir de sua relação com temas de natureza sociocientífica presentes na sociedade contemporânea" (BRASIL, 2014, p. 24) e que esses temas "suscitam debates e controvérsias presentes na vida social" (BRASIL, 2014, p. 24). Coerentes com isso, apresentam a abordagem temática freireana como uma proposta de organização pedagógico-curricular da área.

Ou seja, ainda que as DCN/13 não aprofundem as discussões sobre como os componentes curriculares de $\mathrm{CN}$ podem ser organizados de modo a contribuir para articular as dimensões do trabalho, ciência, tecnologia e cultura, com vistas à 
formação humana integral, documentos elaborados a partir delas explicitam a educação CTS como um caminho.

\section{(4) Edital de convocação do Programa Nacional do Livro Didático de 2015}

No caso do PNLD/15, analisamos o item "Princípios e critérios de avaliação para a área de Ciências da Natureza e suas Tecnologias" do Edital de convocação e identificamos recomendações que têm relação com a educação CTS, como as especificadas abaixo:

\footnotetext{
Para o componente curricular Química será observado se a obra: [...] apresenta o conhecimento químico de forma contextualizada, considerando dimensões sociais, econômicas e culturais da vida humana em detrimento de visões simplistas acerca do cotidiano estritamente voltadas à menção de exemplos ilustrativos genéricos que não podem ser considerados significativos enquanto vivência; [...]. (BRASIL, 2013, p. 65, grifo nosso).

Para o componente curricular Física será observado se a obra: [...] propõe discussões sobre as relações entre ciência, tecnologia, sociedade e ambiente, promovendo a formação de um cidadão capaz de apreciar e de posicionar-se criticamente diante das contribuições e dos impactos da ciência e da tecnologia sobre a vida social e individual; [...]. (BRASIL, 2013, p. 66 , grifo nosso).
}

Nesses fragmentos, é possível identificar e associar clara alusão à perspectiva CTS. No primeiro fragmento (da p. 65), há menção a um dos fundamentos da educação CTS, a contextualização (SANTOS, 2007). Associado a isso, é enfatizada a necessidade de que a obra apresente o conhecimento científico de forma contextualizada e inter-relacionada a dimensões da vida humana. No fragmento seguinte (da pág. 66), as discussões sobre as relações CTS são explicitadas com forte apelo à formação para a cidadania, tendo como um dos pretensos desdobramentos à essa formação, o posicionamento crítico do educando, na sociedade.

Apesar disso, cumpre-nos realçar desdobramentos dessa política educacional, voltada para o livro didático, que dizem respeito às obras aprovadas no âmbito deste programa. Nesse sentido, destacamos, a análise realizada por Fernandes Sobrinho (2016) que aponta que os 14 livros didáticos de Física, aprovados no PNLD/2015, de alguma forma, incorporam elementos da contextualização, indicando aproximação aos fundamentos da educação CTS. Ou seja, há neles, textos (poucos) que abrem possibilidades para discussões CTS, porém, a maioria ainda traz uma concepção centrada em conteúdos específicos com ênfase em algoritmos matemáticos. Assim, destacamos que embora haja sinalizações no edital analisado, as obras em si apresentam poucos espaços para discussões CTS.

\section{(5) Matriz de referência do Enem de 2016}

Quanto à análise da MR-ENEM/16, destacamos que não encontramos referência explicita à terminologia CTS. Apesar disso, identificamos algumas questões que remetem a essa perspectiva educacional, mais especificamente, as relacionadas à: a) participação social e b) humanização das ciências. 
A categoria a) participação social, comparece sob diferentes perspectivas nas competências e habilidades da MR-ENEM. A título de exemplificação, apresentamos considerações sobre as três competências descritas a seguir: Competência de área 1 - Compreender as ciências naturais e as tecnologias a
elas associadas como construções humanas, percebendo seus papeis nos
processos de produção e no desenvolvimento econômico e social da
humanidade.

Competência de área 2 - Identificar a presença e aplicar as tecnologias associadas às ciências naturais em diferentes contextos.

Competência de área 3 - Associar intervenções que resultam em degradação ou conservação ambiental a processos produtivos e a instrumentos ou ações científico-tecnológicas. (BRASIL, 2016a, p. 8).

Na competência 1, percebe-se uma preocupação com a compreensão das transformações sociais acarretadas pelo desenvolvimento científico-tecnológico, o que sinaliza para uma perspectiva de participação social que deve ocorrer em um plano mais amplo, envolvendo uma análise de natureza histórica e decisões coletivas (STRIEDER, 2012). Por outro lado, na competência 2 comparece uma perspectiva de participação atrelada ao saber usar e tomar decisões referentes ao uso, as quais, como já mencionado, estão relacionadas à uma visão de tecnologia enquanto aparato criado para satisfazer as necessidades humanas, ou seja, à uma educação CTS menos crítica. Por fim, na competência 3 e nas habilidades a ela associadas, comparece uma preocupação com a avaliação de aspectos positivos e negativos associados às implicações da ciência e da tecnologia na sociedade, a exemplo da biotecnologia. Como aponta uma das habilidades dessa competência, para a avaliação dos impactos ambientais deve-se levar em conta interesses contraditórios; o que indica uma perspectiva de participação mais crítica, que reconhece que há propósitos distintos e que a avaliação de benefícios e malefícios sempre deve ser analisada considerando o contexto, pois uma efetiva democratização de processos decisórios implica uma ampliação do espectro de dimensões que balizam a fundamentação e a argumentação, presentes no campo axiológico, no âmbito dos juízos de valor e no campo político (AULER, 2011).

No que se refere à humanização das ciências, destacamos duas competências que guardam relação com o ensino de componentes curriculares da área (Biologia, Física e Química), e que revelam duas tendências que possuem vínculos com a educação CTS. Primeiramente, esclarecemos que a expressão "humanização das ciências" atrela-se à ideia de romper com o ensino de ciências em uma perspectiva linear, de memorização, positivista e acrítica que, dificilmente remete a reflexões acerca de aspectos mais políticos, sociais, econômicos e filosóficos, em favor do desenvolvimento humano. Em larga medida, esta humanização das ciências se entrelaça com a educação CTS, marcadamente orientada para o desenvolvimento de ações fortemente relacionadas com questões sociais impactadas pela C\&T.

Assim a primeira delas surge na competência de área 1, por destacar a compreensão das ciências da natureza e as tecnologias a elas associadas como: "construções humanas, percebendo seus papéis nos processos de produção e no desenvolvimento econômico e social da humanidade". (BRASIL, 2016a, p.8). Em contraposição à neutralidade científica, essa competência de área realça a humanização da ciência e da tecnologia, como é possível depreender do excerto 
apresentado. Assinalamos, ainda, o teor de suas correspondentes habilidades, que apresentam verbos como reconhecer, associar, confrontar, avaliar e que sugerem aspectos relacionados à atividade humana. Por exemplo, relacionar fenômenos a diferentes contextos no possibilita pensar no: escolar, social, político, entre outros. Associar comunicação, transporte e saúde ao desenvolvimento científicotecnológico e confrontá-lo com interpretações em diferentes culturas, denotam preocupações marcadamente no âmbito da sociedade. Avaliar intervenções ambientais, considerando a qualidade de vida, não nos deixa dúvidas quanto às discussões de impactos e transformações, no contexto socioambiental, entrelaçando a C\&T com a sociedade.

A segunda relação aparece na Competência de área 6 "Apropriar-se de conhecimentos da física para, em situações problema, interpretar, avaliar ou planejar intervenções científico-tecnológicas" (BRASIL, 2016a, p. 9, grifo nosso). Que, apesar de remeter explicitamente o leitor à Física, a habilidade H21, menciona leis químicas, a H22, implicações biológicas e a H23, contemplam possibilidades que inter-relacionam as três componentes curriculares da área. Aqui, a humanização sugere a noção de corpus frente a alguns ASC, ou seja, para além da interpretação de processos naturais destaca as implicações sociais, econômicas, ambientais e éticas.

\section{(6) Base Nacional Comum Curricular - 2a versão preliminar}

Com relação ao documento preliminar da BNCC-2016 (BRASIL, 2016b), destacamos quatro aspectos, relacionados: a) aos objetivos formativos da área; b) às questões sociocientíficas (QSC); c) à interdisciplinaridade; d) à capacidade de argumentar. No entanto, esclarecemos que como se trata de um documento ainda em construção, acreditamos que tais sinalizações mereçam um olhar futuro mais crítico.

Quanto aos objetivos gerais da área de Ciências da Natureza para o Ensino Médio, identificamos, entre os dez anunciados no documento, pelo menos quatro diretamente relacionados à educação CTS, quais sejam:

\footnotetext{
Interpretar e discutir relações entre a ciência, a tecnologia, o ambiente e a sociedade, em seu próprio contexto e em âmbito maior no espaço e no tempo. Mobilizar conhecimentos científicos para emitir julgamentos e tomar posições a respeito de situações e problemas de interesse pessoal e social, relativos às interações da ciência na sociedade. Desenvolver senso crítico e autonomia intelectual no enfrentamento de problemas e na busca de soluções, visando a transformações sociais e à construção da cidadania. Refletir criticamente sobre valores humanos, éticos e morais relacionados à aplicação dos conhecimentos científicos e tecnológicos (BRASIL, 2016b, p. 584-585, grifo nosso)
}

Esses objetivos se vinculam à educação CTS, uma vez que exigem interpretações e discussões acerca das relações entre C\&T, no tempo e no espaço, sugerindo que o ensino de Ciências deve ir além da mera transmissão e fixação de conceitos e equações, que contribuem para uma formação fragilizada do estudante, diante da recorrente e simples repetição de respostas prontas.

Também, destacamos que o documento menciona a abordagem de QSC, em específico, nos componentes curriculares de Biologia e Química. No caso do 
conhecimento biológico, as QSC são vistas como propulsoras para a contextualização histórica, social e cultural (ver p.188); e no que compete ao ensino de Química, para a formação de um cidadão crítico e participativo (ver p. 224). Cabe esclarecer que as QSC/temas sociocientíficos/controvérsias sociocientíficas se constituem em temas CTS que necessariamente envolvem discussões de ASC, em específico, os valores éticos e morais (SILVA, 2016). Ou seja, de acordo com Silva (2016), as QSC se caracterizam pela relação de três elementos conceituais: a) científico-tecnológico: indica as inter-relações CTS; b) valorativo: explicita os valores éticos e morais e; c) multidisciplinar: representa a multiplicidade de saberes e, portanto, são compreendidas como temas que abordam controversas relativas aos âmbitos científico-tecnológico e social.

Apesar disso, há uma série de questões que parecem se distanciarem de uma abordagem CTS, a exemplo da interdisciplinaridade que se encontra ausente nos excertos relacionados às componentes curriculares das CN. Também, o documento considera que as $\mathrm{CN}$ no Ensino Médio devem contribuir para que o estudante seja capaz de discutir com opinião, temas diversos e tenha condições de transformar essa opinião em um texto escrito, preferencialmente argumentativo. Essa preocupação aproxima-se da defendida no âmbito da educação CTS, porém, para além dessa capacidade argumentativa, identificamos a necessidade de se incorporar níveis mais complexos de habilidades. A título de exemplo desses níveis de complexidade, verbos como "localizar", "identificar" se revelam com baixo teor de complexidade. Já verbos como "integrar", "comparar", "avaliar" exigem habilidades mais complexas do estudante e esses estão pouco presentes no documento analisado.

\section{CONSIDERAÇÕES FINAIS}

A análise dos documentos oficiais brasileiros para o ensino médio, publicados a partir da década de 1990, indica que há uma proposição curricular que aponta para a abordagem CTS. Em todos os documentos analisados encontramos sinalizações da educação CTS, seja por meio de menções às inter-relações CTS e/ou via discussões relacionadas à cidadania, aos objetivos formativos da área de $\mathrm{CN}$, à abordagem de ASC, QSC, interdisciplinaridade, contextualização, temas, participação social, humanização das ciências, etc.

Contudo, esses documentos também apresentam lacunas e ambiguidades. Alguns conceitos, como os de cidadania, interdisciplinaridade, contextualização e abordagem de temas, por exemplo, dão margem a inúmeras interpretações, o que pode contribuir para práticas educacionais que se afastam de uma perspectiva crítica de educação CTS. Esses resultados estão no mesmo sentido do que foi obtido por Roehrig e Camargo (2014) ao analisarem as diretrizes curriculares de Física do estado do Paraná; de Ricardo (2005) sobre os termos competências, interdisciplinaridade e contextualização presentes nos PCNEM; e, de Lopes (2002; 2004), sobre conceitos híbridos relacionados às competências evidenciadas nos documentos curriculares.

Associado a isso, cabe um questionamento: Os documentos contribuem para que os professores tenham clareza sobre a abordagem das inter-relações CTS? Esse questionamento se faz necessário porque, assim como Santos e Mortimer (2002), entendemos que não é suficiente inserir mudanças nos documentos 
curriculares sem promover, de forma articulada, mudanças nas concepções e na prática pedagógica dos professores, até porque crenças e atitudes sobre cidadania, tecnologia, ASC, interdisciplinaridade, contextualização e abordagem temática, interferem nas práticas didático-pedagógicas dos docentes.

Diante disso, para ampliar as possibilidades de inserção de propostas CTS na educação básica é preciso discutir essa perspectiva educacional em cursos de formação inicial e continuada de professores. Nesse intuito, a constituição do saber docente é construída por meio da análise sócio-histórica-filosófica dos conteúdos específicos da área de formação associados às práticas de ensino. Isso por sua vez, implica uma análise situada dos ASC nos quais são considerados indicativos para o planejamento de proposições curriculares embasadas na educação CTS. Também, ressaltamos que as propostas curriculares não podem ser definidas como apontamentos únicos para as mudanças no campo do currículo. Nesse sentido, é preciso ampliar as discussões para além das proposições contidas nos documentos curriculares oficiais, o que necessariamente envolve uma análise acerca do currículo e do planejamento constituídos sócio-historicamente, ou seja, em tempos e espaços específicos. As discussões no contexto das escolas, tendo como pano de fundo pressupostos teóricos sobre o currículo, planejamento, políticas públicas, e as práticas docentes, a nosso ver, tendem a contribuir com a dinâmica de implantação das novas propostas, em uma perspectiva crítica e inovadora. 


\title{
Has STS education been supported by brazilian standards?
}

\begin{abstract}
In this article, we discussed challenges and opportunities related to practices STS, in the context of Brazilian science education. To this end, we analyzed official documents geared towards the science education and the secundary school, published after the current Law of National Education. The results indicate that STS science education has supported by Brazilian official documents, although in the way no much more critical. We concluded that STS education is feasible in the Brazilian education and it expansion needs discussion, critically, in teacher training courses.
\end{abstract}

KEYWORDS: STS. Secondary School. Educacional standards. 


\section{REFERÊNCIAS}

AMORIM, A.C. O Ensino de Biologia e as Relações entre C/T/S: o que dizem os professores e o currículo do Ensino Médio? Dissertação de Mestrado:

Universidade de Campinas, Campinas, 1995.

AULER, D. Enfoque ciência-tecnologia-sociedade: pressupostos para o contexto brasileiro. Ciência \& Ensino, 2007. v. 1, n. especial, p. 1-20.

AULER, D. Novos caminhos para a Educação CTS: ampliando a participação. In: SANTOS, W.L.P.dos; AULER, D.(Orgs.). CTS e Educação Científica: Desafios, Tendências e Resultados de Pesquisas Brasília: Editora UnB, 2011, p. 73-97.

AULER, D.; DELIZOICOV, D. Alfabetização científico-tecnológica para quê? Ensaio: Pesquisa em Educação em Ciências, v. 3, n. 1, p. 105-115, 2001.

AULER, D.; DELIZOICOV, D. Investigação de temas CTS no contexto do pensamento latino-americano. Linhas Críticas, v.21, n. 45, p. 275-296, 2015.

BRASIL. Lei de Diretrizes e Bases da Educação Nacional, Lei no 9.394, de 20/12/1996.

BRASIL. Conselho Nacional de Educação. Resolução n. 3, de 26 de junho de 1998. Institui as Diretrizes Curriculares Nacionais para o Ensino Médio. Diário Oficial da República Federativa do Brasil, Brasília, 5 ago. 1998a. Disponível em:

http://portal.mec.gov.br/cne/arquivos/pdf/rceb03 98.pdf. Acesso em 13 de out. 2016.

BRASIL. Conselho Nacional de Educação. Parecer n. 15, de 1 de junho de 1998. Diretrizes Curriculares Nacionais para o Ensino Médio. Brasília, 1998b. Disponível em: http://portal.mec.gov.br/cne/arquivos/pdf/1998/pceb015 98.pdf. Acesso em 13 de out. 2016.

BRASIL. Ministério da Educação. Parâmetros Curriculares Nacionais: Ensino Médio. Brasília: MEC/SEMTEC, 1999. Disponível em:

http://portal.mec.gov.br/seb/arquivos/pdf/ciencian.pdf. Acesso em 13 de out. 2016.

BRASIL. Ministério da Educação. PCN+ Ensino Médio: orientações educacionais complementares aos Parâmetros Curriculares Nacionais: Ciências da Natureza, Matemática e suas Tecnologias. Brasília: MEC, SEMTEC, 2002. Disponível em: http://portal.mec.gov.br/seb/arquivos/pdf/CienciasNatureza.pdf. Acesso em 13 de out. 2016. 
BRASIL. Ministério da Educação. Orientações Curriculares para o ensino médio: Ciências da natureza, matemática e suas tecnologias. Brasília: MEC/SEB, 2006. Disponível em:

http://portal.mec.gov.br/seb/arquivos/pdf/book volume 02 internet.pdf. Acesso em 13 de out. 2016.

BRASIL. Ministério da Educação. Diretrizes Curriculares Nacionais Gerais da Educação Básica. Brasília: MEC, SEB, DICEI, 2013a. Disponível em:

http://portal.mec.gov.br/index.php?option=com docman\&view=download\&alias $=15548$-d-c-n-educacao-basica-nova-pdf\&Itemid=30192. Acesso em 13 de out. 2016.

BRASIL. Ministério da Educação. Edital de convocação para o processo de inscrição e avaliação de obras didáticas para o Programa Nacional do Livro Didático. Brasília, 2013b. Disponível em: http://www.fnde.gov.br/programas/livro-didatico/livro-didatico-editais. Acesso em 13 de out. 2016.

BRASIL. Ministério da Educação. [autores: Daniela Lopes Scarpa... et al.]. Formação de professores do ensino médio. Pacto Nacional pelo Fortalecimento do Ensino Médio. Etapa II - Caderno III: Ciências da Natureza. Curitiba: UFPR/Setor de Educação, 2014. Disponível em: http://pactoensinomedio.mec.gov.br/images/pdf/cadernos/web caderno 2 3.p df. Acesso em 13 de out. 2016.

BRASIL. Ministério da Educação. Matriz de Referência para o ENEM 2016. Brasília, Distrito Federal, 2016a. Disponível em: http://download.inep.gov.br/educacao basica/enem/downloads/2012/matriz re ferencia enem.pdf. Acesso em 13 de out. 2016.

BRASIL. Ministério da Educação. Base Nacional Comum Curricular - Proposta preliminar. 2a versão revista em abril. Brasília, Distrito Federal, 2016b. Disponível em: http://basenacionalcomum.mec.gov.br/documentos/bncc2versao.revista.pdf. Acesso em 13 de out. 2016.

CUNHA, M.B. O novo ensino médio e o exercício da cidadania: controvérsias e desafios. Dissertação de Mestrado: Universidade Estadual Paulista "Júlio de Mesquita Filho", Marília, 2005.

DAGNINO, R.; SILVA, R.B. da; PADOVANNI, N. Por que a educação em ciência, tecnologia e sociedade vem andando devagar? In: SANTOS, W.L.P.dos e AULER, D. (Orgs.). CTS e Educação Científica: Desafios, Tendências e Resultados de Pesquisas. Brasília: Editora UnB, 2011, p. 99-134. 
FREIRE, P. Pedagogia do oprimido. Rio de Janeiro: Paz e Terra, 1970.

GARCÍA, M.G.; CEREZO, J.A.L.; LÓPEZ, J.L.L. Ciencia, tecnologia y sociedade: una introducción al estúdio social de la ciência y la tecnologia. Madrid - ESP: Tecnos, 1996.

LEODORO, M.P. A educação científica pelos artefatos tecnológicos. R.B.E.C.T., vol.1, n.3, set/dez de 2008.

LENOIR, Y. Didática e interdisciplinaridade: uma complementaridade necessária e incontornável. In: FAZENDA, I.C.A. (Org). Didática e interdisciplinaridade. 6. ed. Campinas: Papirus, 2001.

LOPES, A.C. Conhecimento escolar: ciência e cotidiano. Rio de Janeiro: EDUERJ, 1999.

LOPES, A.C. Os Parâmetros Curriculares Nacionais para o ensino médio e a submissão ao mundo produtivo: o caso do conceito de contextualização.

Educação \& Sociedade, São Paulo, v. 23, n. 80, p. 389-404, 2002.

LOPES, A.C. Políticas de currículo: mediação por grupos disciplinares de ensino de ciências e matemática. In: LOPES, A.C.; MACEDO, E. (Orgs.). Currículo de ciências em debate. Campinas: Papirus, p. 45-75, 2004.

MOEHLECKE, S. O ensino médio e as novas diretrizes curriculares nacionais: entre recorrências e novas inquietações. Revista brasileira de educação, v. 17, n. 49, p. 39-58, 2012.

MORAES, R.; GALIAZZI, M.C. Análise Textual Discursiva. Ijuí: Editora Unijuí, 2007.

ORIANI, A.P. A concepção de cidadania nas diretrizes curriculares nacionais para o ensino médio. Revista de iniciação científica da FFC, v. 7, n. 3, p. 307-321, 2007.

PAIVA, S.N.; KAWAMURA, M.R.D. Aspectos curriculares nas diretrizes e documentos curriculares nacionais nos últimos anos. Atas do XVI Encontro de Pesquisa em Ensino de Física, Natal, 2016. 
PINHEIRO, N.A.M.; SILVEIRA, R.M.C.F.; BAZZO, W.A. Ciência, tecnologia e sociedade: a relevância do enfoque CTS para o contexto do ensino médio. Ciência \& Educação, v. 13, n. 1, p. 71-74, 2007.

RICARDO, E.C. Competências, interdisciplinaridade e contextualização: dos parâmetros curriculares nacionais a uma compreensão para o ensino das ciências. Tese de Doutorado: Universidade Federal de Santa Catarina, Florianópolis, 2005.

ROEHRIG, S.A.G.; CAMARGO, S. Educação com enfoque CTS em documentos curriculares regionais: o caso das diretrizes curriculares de física do estado do Paraná. Ciência \& Educação, v. 20, n. 4, p. 871-887, 2014.

SANTOS, W.L.P. dos. Educação científica: Uma revisão sobre suas funções para a construção do conceito de letramento científico como prática social. Revista Brasileira de Educação, v. 12, n. 36, p. 474-492, 2007.

SANTOS, W.L.P. dos. Educação científica humanística em uma perspectiva freireana: resgatando a função do ensino de CTS. Alexandria: Revista de Educação em Ciência e Tecnologia, v. 1, n. 1, p. 109-131, 2008.

SANTOS, W.L.P. dos. Educação CTS e cidadania: confluências e diferenças. Amazônia - revista de educação em ciências e matemáticas, v. 9, n. 17, p. 49-62, 2012.

SANTOS, W.L.P. dos; MORTIMER, E.F. Uma análise de pressupostos teóricos da abordagem C-T-S (Ciência-Tecnologia-Sociedade) no contexto da educação brasileira. Ensaio: Pesquisa em Educação em Ciências, v.2, n. 2, p. 1-23, 2002.

SANTOS, W.L.P. dos; MORTIMER, E.F. Abordagem de aspectos sociocientíficos em aulas de ciências: possibilidades e limitações. Investigações em Ensino de Ciências, v. 14, n. 2, p. 191-218, 2009.

SILVA, K. M. A. Abordagem CTS no ensino médio: um estudo de caso da prática pedagógica de professores de Biologia. Dissertação de Mestrado: Universidade Federal de Goiás, Goiânia, 2010.

SILVA, K.M.A. Questões Sociocientíficas e o Pensamento Complexo: Tecituras para o ensino de Ciências. Tese de Doutorado: Universidade de Brasília, Brasília, 2016. 
STRIEDER, R.B. Abordagens CTS na educação científica no Brasil: sentidos e perspectivas. Tese de Doutorado: Universidade de São Paulo, São Paulo, 2012.

TOTI, F.A. Educação científica e cidadania: as diferentes concepções e funções do conceito de cidadania nas pesquisas em educação em ciências. Tese de Doutorado: Universidade Federal de São Carlos, São Carlos, 2011.

Recebido: 10 out. 2016

Aprovado: 14 out. 2016

DOI: $10.3895 /$ actio.v1n1.4795

Como citar:

STRIEDER, R. B. et al. A educação CTS possui respaldo em documentos oficias brasileiros?. ACTIO,

Curitiba, v. 1, n. 1, p. 87-107, jul./dez. 2016. Disponível em: <https://periodicos.utfpr.edu.br/actio>. Acesso em: $X X X$.

Correspondência:

Roseline Beatriz Strieder

SQN 214, BI. E, Ap. 302, Asa Norte, Brasília, Distrito Federal, Brasil.

Direito autoral: Este artigo está licenciado sob os termos da Licença Creative Commons-Atribuição 4.0

Internacional.

(c) (1) 